\section{Nanobiomaterials for vascular biology and wound manage- ment: A review}

Ajay Vikram Singh, ${ }^{1}$ Donato Gemmati, ${ }^{2}$ Anurag Kanase, ${ }^{3}$ Ishan Pandey, ${ }^{4}$ Vatsala Misra, ${ }^{5}$ Vimal Kishore, ${ }^{1}$ Timotheus Jahnke, ${ }^{6}$ Joachim Bill $^{6}$

${ }^{1}$ Max Planck Institute for Intelligent Systems, Stuttgart, Germany;

${ }^{2}$ Hemostasis \& Thrombosis Center, University Hospital of Ferrara, Ferrara, Italy; ${ }^{3}$ Molecules in Motion Pvt. Ltd, Pune, India; ${ }^{4}$ Department of Microbiology, Motilal Nehru Medical College, Allahabad, India; ${ }^{5}$ Department of Pathology, Motilal Nehru Medical College, Allahabad, India; ' Institute for Materials Science, University of Stuttgart, Stuttgart, Germany

\section{Abstract}

Nanobiomaterials application into tissue repair and ulcer management is experiencing its golden age due to spurring diversity of translational opportunity to clinics. Over the past years, research in clinical science has seen a dramatic increase in medicinal materials at nanoscale those significantly contributed to tissue repair. This chapter outlines the new biomaterials at nanoscale those contribute state of the art clinical practices in ulcer management and wound healing due to their superior properties over traditional dressing materials. Designing new recipes for nanobiomaterials for tissue engineering practices spanning from micro to nano-dimension provided an edge over traditional wound care materials those mimic tissue in vivo. Clinical science stepped into design of artificial skin and extracellular matrix components emulating the innate structures with higher degree of precision. Advances in materials sciences polymer chemistry have yielded an entire class of new nanobiomaterials ranging from dendrimer to novel electrospun polymer with biodegradable chemistries and controlled molecular compositions assisting wound healing adhesives, bandages and controlled of therapeutics in specialized wound care. Moreover, supportive regenerative medicine is transforming into rational, real and successful component of modern clinics providing viable cell therapy of tissue remodeling. Soft nanotechnology involving hydrogel scaffold revolutionized the wound management supplementing physicobiochemical and mechanical considerations of tissue regeneration. Moreover, this chapter also reviews the current challenges and opportunities in specialized nanobiomaterials formulations those are desirable for optimal localized wound care considering their in situ physiological microenvironment.

\section{Introduction}

Nanomedicine is providing explosive development to complement and augment clinical and biomedical practices in wound healing and ulcer management due to its better therapeutic outcome. ${ }^{1}$ Atomic level control of nanobiomaterials exhibit quantum characteristics compared to their bulk materials and when combined with biological properties, biomolecules exhibit entire new phenomenon in this magic dimension. This is the main reason that nanomedicine is preferred over traditional biomedical practices in recent years. By National Institute of Health (NIH) definition, nanomedicine describes use of nanotechnology in biology and medicine ranging from biomedical applications to molecular nanotechnology and nanoelectronics in developing biosensors for diagnosis and therapeutics.,3 Lately, nanoparticles (NPs) have been variously used in targeted drug delivery to improve bioavailability and systemic circulation of drug and an insight into this is reflected by the fact that annual investment in nanobiomaterials has increased to 3.8 billion USD. ${ }^{4}$ In past, targeted drug delivery was one of most sought nightmare of pharmaceutical industry. Dendrimer polymer and lipid based drug delivery system had contributed immensely in this regard. Dimensional benefits of NPs provide an opportunity to adapt in systemic circulation and move through the cell membranes and are concentrated and accumulated inside cytoplasm. Design of biodegradable NPs, e.g. nanoliposomes, nanospheres, nanocapsule, hollow nanostructures, ceramic NPs, dendrimers and polymeric micelles have their own advantages over traditional drug delivery system ${ }^{5,6}$ (Figure 1). They provide sustained release of drug at target sites and can be maintained for longer period in systemic circulations. ${ }^{7}$

Most important characteristic that attracted these nanomaterials to ambitious researchers for drug delivery, emerges from their easy and reliable surface modification for tissue/organ specific targeting. ${ }^{8}$ In this context, to catalyze the pharmaceutical innovation in vascular biology, a strategic and legislative effort was made via
Correspondence: Ajay Vikram Singh, Max Planck Institute for Intelligent Systems, Heisenbergstr. 3, 70569 Stuttgart, Germany. E-mail: avsingh@is.mpg.de

Key words: Venous leg ulcer; nanomaterials; hydrogel; dendrimers; organ-on-chip.

Acknowledgments: AVS thanks Max Planck Society for the grass root project grant 2017 (M10335) and 2018 (M10338).

Conflict of interests: the authors declare no potential conflict of interests.

Received for publication: 16 November 2017.

Revision received: 28 January 2018.

Accepted for publication: 29 January 2018.

This work is licensed under a Creative Commons Attribution 4.0 License (by-nc 4.0).

CCopyright A.V. Singh et al., 2018

Licensee PAGEPress, Italy

Veins and Lymphatics 2018; 7:7196

doi:10.4081/vl.2018.7196

interviewing patients by the consulting physicians to highlight most transformative medicine in last 25 years. Out of 941 patient, 513 voted the drugs with superior efficiency as most transformative medicine. This could be future logic for vascular nanotherapeutics design as well since nanotechnology has provided tremendous efficacy via vascular nanomedicine ${ }^{9}$ (Table 1).

Question related with the efficacy: This drug had a huge impact on our ability to treat osteoporosis; Spectacular impact on B cell malignancies, and on autoimmune diseases; The most potent class of agents to lower intraocular pressure; Actually modified the course of multiple sclerosis, Although difficult to use, has proven life-saving for many patients with arrhythmias.

Novel mechanism of action: Introduced a new set of compounds for treatment of psychosis; Prototype of an antibody directed to a growth factor receptor that re-energized breast cancer tumour biology as well as proved highly curative as a treatment of selected subsets.

TNF blockers; rheumatology: These drugs first established the paradigm of biological intervention, represented the first class of biological in rheumatology and have made a significant difference in the treatment of rheumatoid arthritis and spondyloarthropathies; Medication that had significant impact on treatment of insulin resistance and helped elucidate underlying mechanism.

Impact on practice in field: Remarkable... for a development strategy 
featuring molecular biomarkers for stratification (BCR-ABL rearrangements) and for pharmacodynamics (receptor autophosphorylation).

Imatinib; oncology: First drug to modify immune response by enhancing it. This is a sentinel therapeutic approach.

Cinacalcet; nephrology: A unique addition to the armamentarium of drugs for renal bone disease. Grew directly out of knowledge gained in basic science research and shows how transformative such work can be.

Nitisinone; medical genetics: First example of substrate depletion as a therapeutic mechanism for an inborn error of metabolism [Disease].

Improved safety: When introduced in 2001, overcame many of the severe toxicities associated with combination ART regimens before this (tenofovir; infectious diseases).

Temozolomide; neurology: Although the effects are modest, it is clear that the ability to have access to a tolerable treatment for gliomas is important and driving future drug

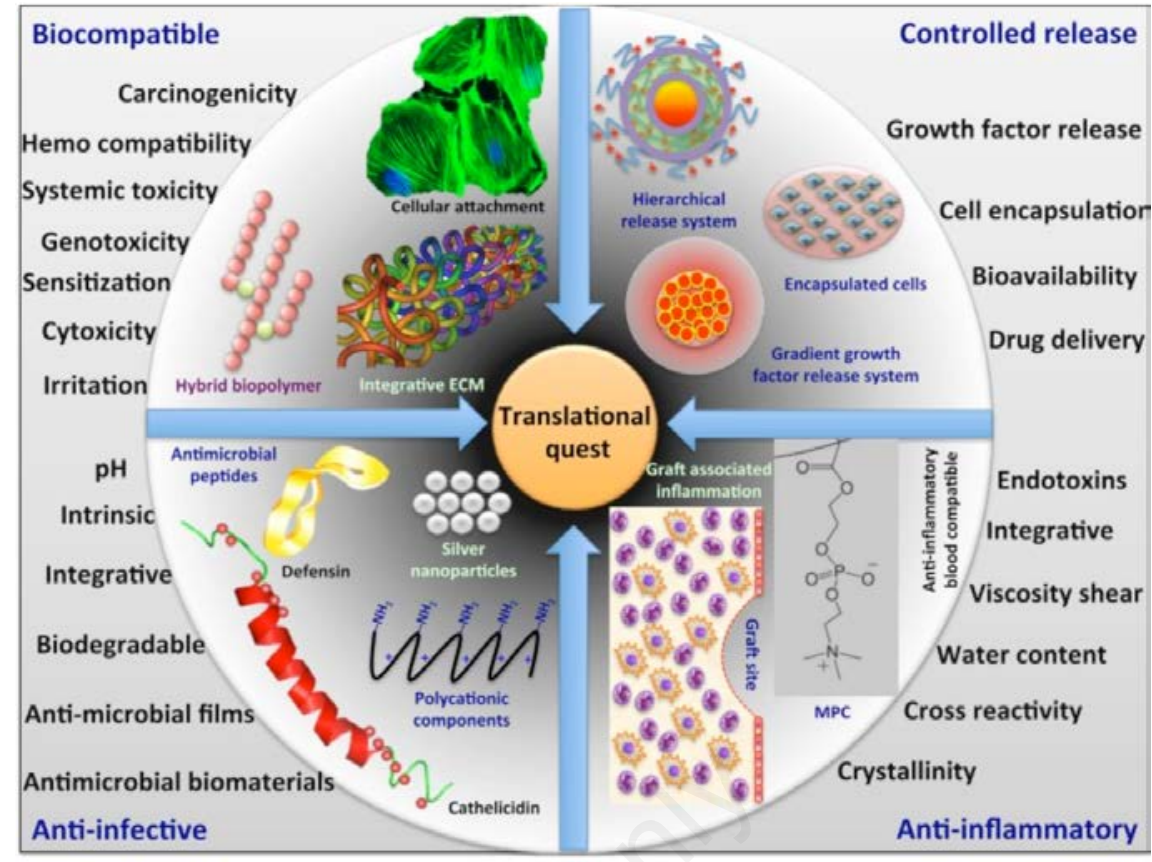

Figure 1. Nanotechnology based translational quest for next generation biomaterials for vascular biology applications (reproduced with permission from ref. ${ }^{6}$ ).

Table 1. Justifications used by study participants to indicate a drug as transformative.

\begin{tabular}{|c|c|c|}
\hline Justification & Freq. $(N=941) ; \mathrm{n}: \%$ * & Illustrative remarks \\
\hline Improved efficacy & $513 ; 55 \%$ & $\begin{array}{l}\text { Alendronate; endocrinology } \\
\text { Rituximab; rheumatology and oncology } \\
\text { Latanoprost; ophthalmology } \\
\text { Interferon beta-la; neurology } \\
\text { Amiodarone; cardiology }\end{array}$ \\
\hline Novel mechanism of action & $345 ; 37 \%$ & $\begin{array}{l}\text { Clozapine; psychiatry } \\
\text { Sildenafil; urology } \\
\text { Trastuzumab; oncology } \\
\text { TNF blockers; rheumatology }\end{array}$ \\
\hline Impact on practice in field & $143 ; 15 \%$ & $\begin{array}{l}\text { Metformin; endocrinology } \\
\text { Imatinib; oncology } \\
\text { Imiquimod; dermatology } \\
\text { Cinacalcet; nephrology } \\
\text { Nitisinone; medical genetics }\end{array}$ \\
\hline Improved safety & $139 ; 15 \%$ & $\begin{array}{l}\text { Tenofovir; infectious diseases } \\
\text { Temozolomide; neurology } \\
\text { Fluoxetine; psychiatry } \\
\text { Propofol; anaesthesiology }\end{array}$ \\
\hline Widespread use and impact & $110 ; 12 \%$ & $\begin{array}{l}\text { Fluoxetine; psychiatry } \\
\text { Enalapril; nephrology } \\
\text { Sildenafil; urology } \\
\text { Omeprazole; gastroenterology }\end{array}$ \\
\hline Ease of patient use & $109 ; 12 \%$ & $\begin{array}{l}\text { Etanercept; rheumatology } \\
\text { Combination fluticasone/salmeterol; } \\
\text { Pulmonary medicine } \\
\text { Zithromax; infectious diseases } \\
\text { Tamsulosin; urology }\end{array}$ \\
\hline Application to multiple diseases & $63 ; 7 \%$ & $\begin{array}{l}\text { Infliximab; rheumatology } \\
\text { OnabotulinumtoxinA; neurology } \\
\text { Rituximab; rheumatology/oncology } \\
\text { Leuprolide; endocrinology }\end{array}$ \\
\hline
\end{tabular}

ACEI, angiotensin-converting enzyme inhibitor; ANCA, anti-neutrophil cytoplasmic antibody; ART, antiretroviral therapy; CKD, chronic kidney disease; PDE5, phosphodiesterase 5; SSRI, selective serotonin reuptake inhibitor; TNF, tumor necrosis factor. *Round 1 responses only. Answers do not sum to 100\% because they were not mutually exclusive. Reproduced from Kesselheim and Avorn, $2013^{9}$ with permission. 
development.

Fluoxetine; psychiatry: Transformed treatment of depression providing effective agent with far fewer side effects and toxicity risks in overdose than tricyclic antidepressants and monoamine oxidase inhibitors. More rapid recovery with less delirium and less postoperative nausea.

Fluoxetine; psychiatry: Widespread use and impact: First [SSRI] to have a major impact worldwide. Ushered in a new era of novel antidepressants.

Enalapril; nephrology: The primary agent that has spawned the widespread use of ACEI in CKD over 25 years.

Sildenafil; urology: It is obvious that this was the number one transforming drug not only in urology but in all of medicine and society in last 25 years.

Omeprazole; gastroenterology: Perhaps the most important proton pump inhibitor; more than 60 million Americans have gastroesophageal reflux disease, many on a daily basis.

Ease of patient use: Huge impact because of the ability to administer the drug at home (in addition to its efficacy).

Combination fluticasone/salmeterol; pulmonary medicine: Inhaled steroids modify natural history but have poor compliance. Adding salmeterol improves compliance.

Zithromax; infectious diseases: The first antibiotic to have both massive use and once daily dosing. First specific alpha-blocker; no dose titration needed.

Infliximab; rheumatology: Application to multiple diseases: First anti-TNF monoclonal antibody approved for multiple clinical indications, including inflammatory bowel disease.

OnabotulinumtoxinA; neurology: This drug completely altered the treatment for focal dystonia. It has also been useful for many conditions outside of dystonia.

Rituximab; rheumatology/oncology: [Established] the central pathogenic role of $\mathrm{B}$ cells in multiple autoimmune diseases including some (rheumatoid arthritis, ANCA vasculitis, type 1 diabetes, multiple sclerosis) not typically considered $B$ cell diseases despite the expression of autoantibodies.

\section{Vascular biology and nanomedicine}

A recent development in material synthesis has given an edge to synthesize biological structures in vitro under ambient lab conditions. These developments coupled with tissue engineering have put forth enormous capabilities of these materials in vascular biology and regenerative medicine.
In biomedicine, vascular biology is one of very advance field that seldom needs technical expertise since this field comprises vast cardiovascular premises surrounded by blood vessel and associated structures. ${ }^{10}$ Advances in nanomedicine have given a languishing hope to future promises in this field due to ground level cooperation between various fields of basic sciences comprising engineering, medicine, physics, chemistry and biology. An in vitro study had revealed that biocompatible nanosurfaces promote growth and proliferation of vascular cells viz. endothelial and smooth muscle cells that paved the way for future vascular stents applications in designing endothelial monolayer. ${ }^{11,12}$

\section{Application of nanomedicine in vascular biology}

Advent and increased sophistication of nanotechnological tools provided us an understanding to develop in vitro biological circuits using smart carbon materials that can be used for neuronal prosthesis in vivo. With
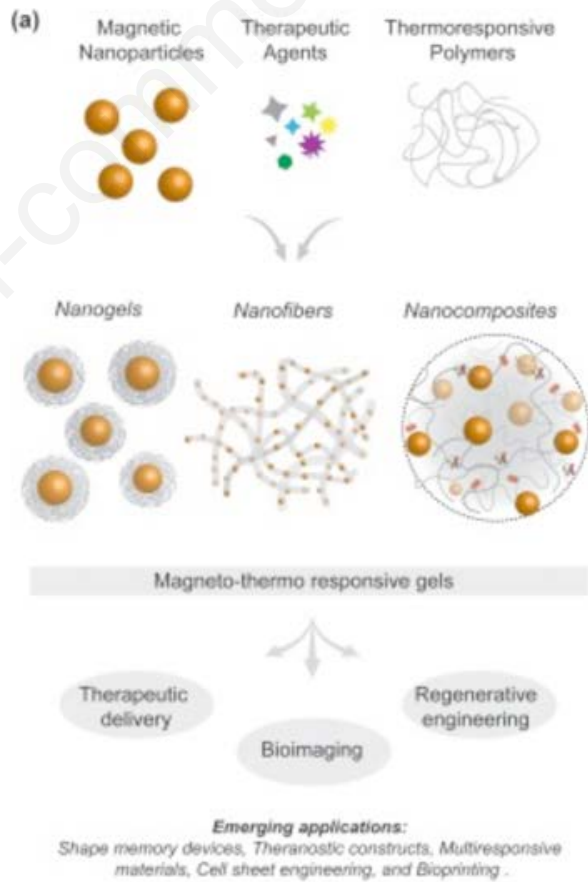

(b)
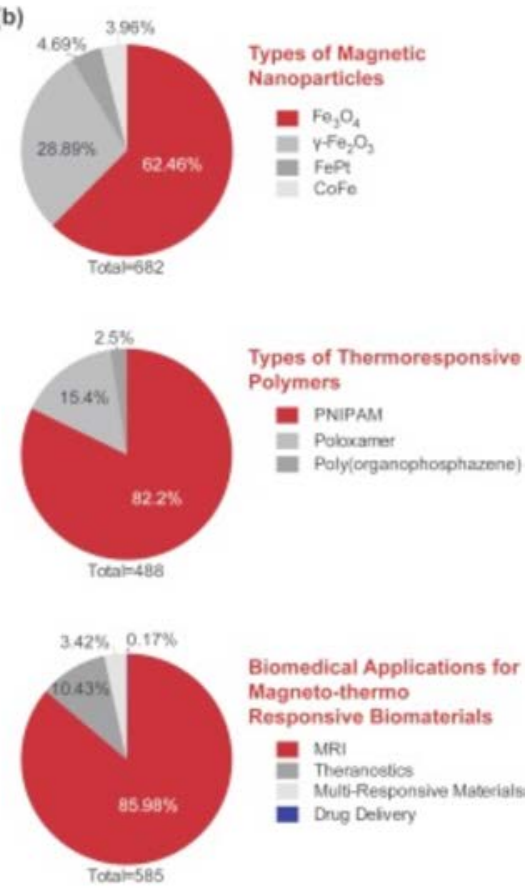

Biomedical Applications for Magneto-thermo Responsive Biomaterials - MRI MRI Therancetics - Drug Delvery

Figure 2. Schematic illustration of nanomaterials used for skin wound therapy: From Nanoparticles to Nanoparticulate Composites. Abbreviations: FMs, films and membranes; HGs, hydrogels; MCs, multicomposites; NFs, nanofibers; NPs, nanoparticles (reproduced with permission from ref.18 with free use Creative Commons Attribution 4.0 International License). 


\section{Nanobiomaterials: New \\ beginning in wound healing and ulcer management}

As updated convention, biomaterials can be defined as substances composed of biologically derived moieties (other than drugs and food) those can be successfully used for therapeutic or diagnostic purposes irrespective of their applications. ${ }^{20}$ In recent years, biomaterials research has gained momentum due to their significant contribution in biology and medicine..$^{21,22}$ Use of biomaterials in tissue engineering is revolutionary rather than evolutionary due to their capabilities to synthesize artificial connective, epithelial, or neuronal tissues. One of major breakthrough supporting nanobiomaterials in medicine is their dimensional versatility that ranges from equiaxed symmetrical gold, ${ }^{7,23,24}$ Platinum, Titanium nanoparticles (NPs), quantum dots (QDs) to one dimensional fibrous forms (carbon nanotubes/fibers) ${ }^{25}$ that make them a suitable choice for wound dressing materials. This dimensional profitability makes them materials of choice in various implants and prosthetic applications where dimensional stability is most important features. For example nanobiomaterials have been used in Zirconium based Joints (hip, knee, shoulder), Cochlear/dental and breast implants, ear and glaucoma drainage tube, mechanical heart valve and articular graft, intra ocular lens, ${ }^{26-33}$ etc. Nanoclay and nanohdyroxyapatite are used to fillers and reinforce agents to strengthen the mechanical stability of polymers in various prosthetic processes. ${ }^{27,34}$ The smart aspect of nanobiomaterials can be evaluated by their smart application in bioelectronics that they not only can touch, feel or stimulate the biological system but also can transmit the information as sensors, biofuels or circuitry elements for versatile biomedical applications that could be another promising approach in design of electronic skin. ${ }^{28,30}$ These could be used in wound management with supported antimicrobial agents as filling materials in deep cuts and burn cases where we need to cover large surface areas to protect skin and promote rapid healing. . $^{2,30}$ The biggest advantages of nanomaterials are their large surface to volume ratio i.e. they can cover large surface area applied. This characteristic provides a unique opportunity in surface healing process where we need minimal therapeutic to cover large area.

\section{Challenges in designing biomate- rials for wound healing and ulcer management}

Challenging aspects that might be considered during design of nanobiomaterials for wound healing must consider required biodegradability, surface properties, mechanical properties, shapability to sculpt finer details ${ }^{31}$ (Figure 3). Some of the challenges in the designing nanobiomaterials are discussed with following areas: i) progress and challenges mimicking ECM biologically and structurally; ii) actively interaction nanostructures, which promote mammalian cell interaction and inhibit bacterial growth; ${ }^{32-34}$ iii) detail list of biomaterials used for biomedical applications (e.g., soft

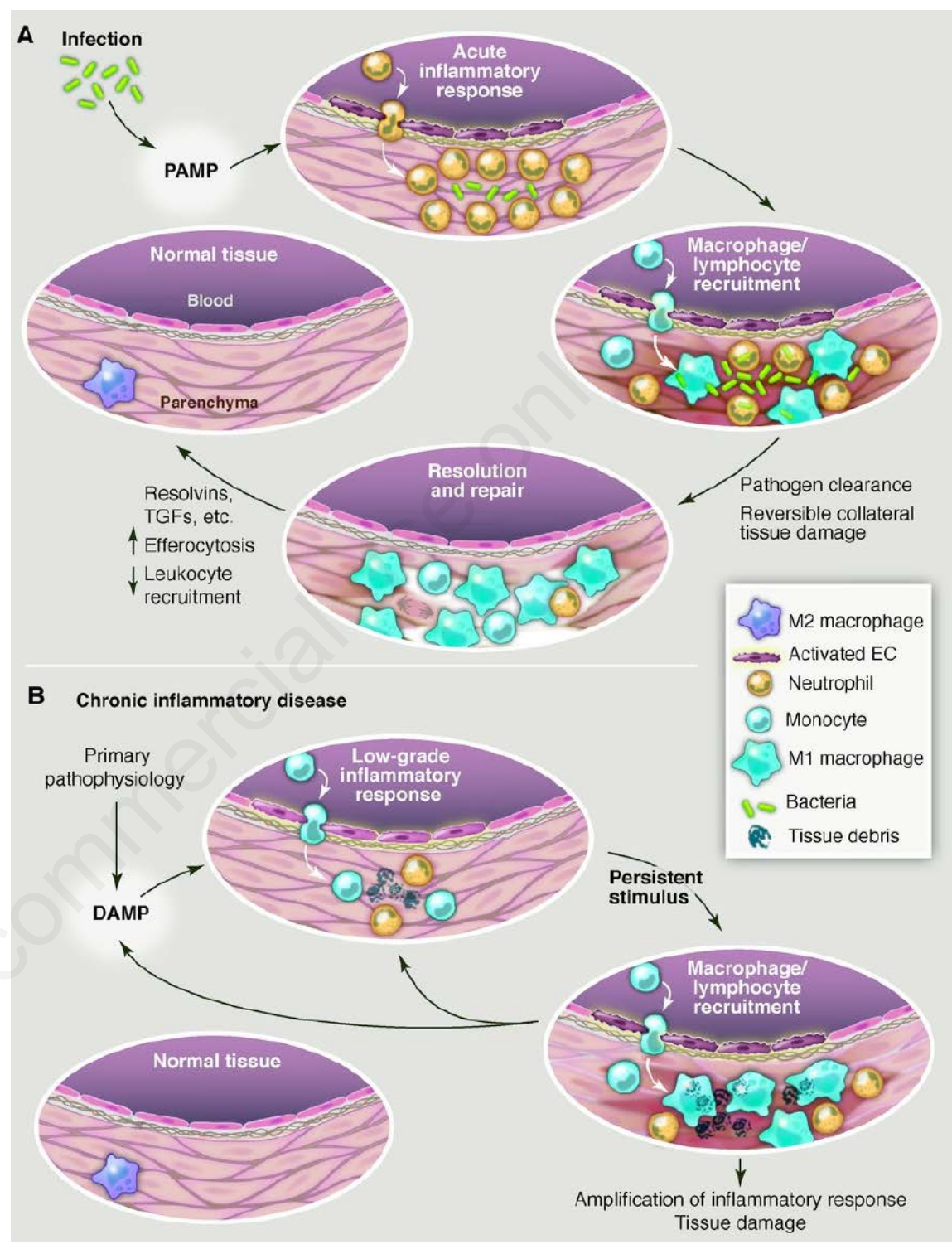

Figure 3. Evolution of resolving versus nonresolving inflammation at a cellular level. (A) Typical features of a normal acute inflammatory response to infection that is detected by presentation of PAMPs to pattern recognition receptors. Eradication of the pathogen eliminates the stimulus, along with causing some reversible collateral tissue damage, and sets the stage for the resolution/repair phase, leading to restoration of normal tissue homeostasis. (B) Typical features of a chronic inflammatory disease caused by a nonimmune pathophysiologic process that in one way or another triggers an initial sterile inflammatory response, often indolent and likely through production of damage-associated molecular patterns (DAMPs). This initial response then becomes amplified by cytokines and chemokines. Because this response does not eradicate the initial stimulus, persistent nonresolving inflammation occurs, ultimately resulting in tissue damage. The inflammatory response itself may positively influence the production of DAMPS, which provides an additional positive feedback loop. For example, in the case of atherosclerosis, reactive oxygen intermediates (ROI) and reactive nitrogen intermediates (RNI) may modify subendothelial lipoproteins in a manner that amplifies their ability to promote inflammation. Adapted with permission from ref. ${ }^{36}$ Tabas et al. 
nanomaterials, hydrogels, fiber scaffold mimicking ECM, dendrimers and electro spun polymers and their advantages) $;{ }^{35}$ iv) corneal wound healing, Bladder wall and vascular biology applications: a special use of biomaterials is required due to complex inflammatory cascade depending upon chronic and acute cases; ${ }^{36} \mathrm{v}$ ) details of advantageous factors those give an edge to nanomaterials for use over traditional one e.g., surface modifications to prohibit nonspecific protein adsorption, pinpoint and accurate immobilization of signaling molecules over required surface, biologically inspired nanofibres to mimic natural ECM structures, arduous and vociferous design of 3-D architecture to develop in vitro blood vessels with supported angiogenesis; ${ }^{15}$ vi) unique surface energy of nanomaterials: protein-mediated cell interactions.

\section{Artificial skin: emerging concept for regenerative medicine}

Designing materials for wound healing and ulcer management had taken one-step forward from traditional materials dissecting the conventional thinking to design dressings and antimicrobial supplement. ${ }^{37}$ The concept and realization of initial steps of designing artificial skin had given a great hope to regain price and prejudice of aesthetic value in burn cases where often patients has to lose a lot in terms of social values due to lost skin textures that leave a scar after treatment. Natural skin transplant will be the first choice for clinicians and surgeons to replace scarred skin in burn cases, nonetheless designing artificial skin will enhance the scope of regenerative, and transplant medicine to underscore the conundrum of success of manmade organ over natural one.

\section{Fundamentals of designing artifi- cial skin}

Skin with integument system makes primary defense barrier against microbes and keeps body surface in tune with the external environment. Histology of skin comprises epidermis composed of stratified squamous epithelium, a dermis having dense connective tissue and fibroblasts with underlying hypodermis with adipose and connective tissue fibers. ${ }^{38}$ Among above two, epidermis is home of ECM forming keratinocyte, melanin producing melancholy and epithelial cells. Considering design of fully functional artificial skin, graft materials should adhere with wounded skin and should be porous enough to allow diffusion of gases, water, nutrients, waste and most importantly prevent dehydration of surrounding wounded skin. Graft materials should allow migration and relocation of cell components and should be comparable with natural skin in mechanical and electronic properties. Finally yet importantly, artificial graft must support regeneration of underlying dermal layer that in turn will support the regeneration of epidermal layer. These advances on one hand will prevent microbial invasion to wound site, on the other hand give an opportunity to fast healing. ${ }^{39}$ Material design for artificial skin graft must fulfill nutrient and growth factor requirement, taking care of immunological aspect to avoid foreign body and prevent rejection of its own. Further, they must have inherent ability to integrate artificial tissue with supporting innate vasculature and must be supplemented with cultured skin cells that makes it truly bioactive and helps in establishing connection with the underlying natural tissue. ${ }^{40}$ Moreover, we need to put the basics on designing skin with mechanoreceptors, pressure and tactile receptors with impregnated hair follicles and nerve branching. One fascinating work had reveled construction of nanotransistors tagged with large area, flexible pressure sensor matrix that eventually work as electronic skin for futuristic nanorobots aimed to surgical procedures in vitro. ${ }^{37,41}$ So for progress made in this area adapted discriminative approaches supplying grafts with cultured epidermal cells in one case, cultured dermal in another case and a supplement of duo in third case. Researcher suggested that grafts with dermal layer after regeneration supports a subsequent auto graft and provide best opportunity in burned tissue regeneration. ${ }^{42}$
Basic design of artificial skin must include the vide-infra scope of chemical composition that leads to the fundamental success of the story. Studies hypothesizing importance of chemical compositions have given insight that collagenglycosaminoglycan (GAG) membranes cross linked with glutaraldehyde (as cross linking agents), used as artificial skin, had shown to have capacity to escape fluid loss and infection over longer period of time (Figure 4).

Most important they prevent graft rejection and contraction of wounds that is of primary importance for cosmetic purposes in facial wounds and functional importance in corneal wounds since contraction in corneal wounds produces astigmatism. ${ }^{43}$ As an evidence, chemically crosslinked glycosaminoglycan (GAG) with hyaluronan (HA) and chondroitin sulfate (CS) as an active ingredients have been shown to perform better wound dressing materials than the traditional one. ${ }^{44}$ Nanobiomaterials have numerous advantages over the traditional one due to their various properties as discussed next.

In terms of thermal sensitivity, traditional biomaterials are moderate due to meso-micro scale modifications in comparison to the nanobiomaterials showing higher thermal sensitivity due to nano scale modification. ${ }^{45}$ The hydrophilicity of nanobiomaterials due to surrounding temperature control $^{46}$ is more than the traditional biomaterials. The nanobiomaterials have higher surfacevolume ratio, ${ }^{47}$ which helps in cell attachments and grafting more than the traditional ones, which have the low protein interaction surface energies. Due to the biological origin and bio-polymers, ${ }^{48}$ nanobiomaterials are superior, in terms of

Figure 4. Schematic plan showing hyaluronan-GAG-core protein cross-linking strategy to design hydrogel based artificial skin-ECM analogue. Fundamental design includes HAGAGs backbone that supports nanoscale protein-carbohydrate monomer buildings blocks pegged meticulously to mimic biostructure (n: repeating units; authors personal communication).

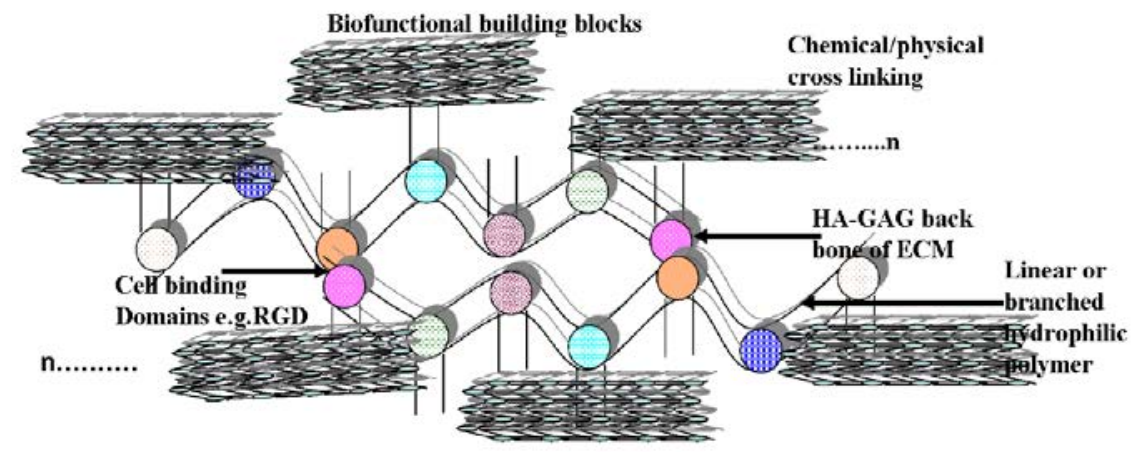


biocompatibility and biodegradability, to traditional biomaterials. Nanobiomaterials also has preferences in terms of hydro retention due to use of hydrogel-based dressing $^{49}$ rather than traditional gauze based dressing materials used in traditional biomaterials. Also nanobiomaterials are more bioadhesive and antimicrobial due to the impregnated antimicrobial supplement into its nanoporous membrane ${ }^{50}$ which is supplied from outside in the conventional biomaterials. However, traditional biomaterials have an advantage concerning the tissue abrasion over nanobiomaterials due to foam-based airfluidized. ${ }^{51}$ With reference to mechanical properties, the usual biomaterials show sufficient strength but less than the nanobiomaterials which have nanopolymer layer. ${ }^{52}$

\section{Designing of biomaterial mimicking ECM using nanoscale tissue engineering}

ECM defines extra cellular part of cell that often provides structural supports to cell and more precisely defines connective tissue. ECM regulates cell's dynamic behavior in terms of intercellular communication and deporting a number of growth factors those helps in cell signaling and cell anchorage in various biological phenomenons. ${ }^{53}$ It becomes an important issue to consider ECM morphology and function when considering design of nanobiomaterials for wound healing and reparative tissue management, as formation of ECM is the fundamental process in morphogenesis, wound healing, growth and fibrosis. Deep understanding ECM components such as proteoglycan and non-proteoglycan (GAGs) that form a matrix by interlocking with the fibrous proteins will help to assemble biological moieties to form artificial ECM membrane for wound healing and burned skin. ${ }^{54}$ ECM contains cell-binding domains those interact with cell receptors and transmit cellular signals to cell-cell/cellECM adhesion and binding. ECM mediated cell signaling also helps in sequestering various bioactive molecules such as fibrous proteins, GAGs, growth factors and cytokines which is important steps in tissue remodeling at wound sites. ${ }^{55}$

\section{In vitro $\mathrm{ECM}$ synthetic analogue}

Artificial design must sketch structural and functional relationship between ECM and biomaterials that can sustain and respond pharmacological action at living tissue and engineered interface. ${ }^{56}$ Some studies had shown nanofibre scaffold mimicking ECM designed by tissue engineering. ${ }^{12,57}$

\section{Dynamic interaction among cell components}

Nanobiomaterials must exhibit a dynamic microenvironment at wound site to facilitate cross talk among soluble (growth factors, cytokines, morphogens) and insoluble components (cells, ECM components) under ambient chemical environment $\left(\mathrm{pH}, \mathrm{O}_{2}\right)^{58}$ to establish a vital connection between the living tissue and nonliving biomaterials. ${ }^{12}$

\section{Tissue regeneration}

Most sought requirement of designing ECM replica should support tissue regeneration at wounded tissue site. This could be achieved by meticulous surface modification of proteins and cell binding domains and incorporation of such ligands (RGD, IKVAV) in molecular design. The scaffold must provide a guided mechanical platform for new skin growth. ${ }^{59}$

\section{Active cellular/tissue responses}

Biomaterials design so for give nonspecific responses towards biological system due to inappropriate design of cellular components. This is major challenge to today's material research to pinpoint the target specific receptor to respond cellular functions viz. adhesion, proliferation and differentiation in artificial design of molecular components. This needs controlled incorporation of cell binding and enzymatic sequences sites in bioactive design.

\section{Specialized application of soft nanomaterials}

\section{Corneal wound healing}

Corneal wounds repair is of paramount importance as cornea is site of refraction and focusing light in order to make correct vision. Non-vascular nature and patterned collagen fibrils provide characteristics transparency to cornea that makes it special tissue for normal vision. Corneal wounds are caused due to a number of reasons including corneal ulcer, ocular surgery (intraocular implantations, incisions for cataract surgery, in situ keratomileusis and transplants) and trauma caused by lacerations or perforations. Currently, nylon sutures are choice of surgical procedures but they achieved cold reception from clinicians due to some undesired properties. Nylon sutures often cause wound constrictions and asymmetrical healing that often leads to astigmatism.
Moreover, suture and incision during ocular surgery inflicts additional trauma to corneal tissue and thus inflammations and vascularization ending into corneal scar that contribute significantly to astigmatism. More often, sutures need special attention and technical skills by trained ophthalmologists in order to avoid postoperative loosening and corneal trauma during in and out of suture removal. ${ }^{60}$ Therefore, technological skills to design new surgical materials and tools constitute competitive race in this field in order to restore natural vision and patient care in ophthalmic and corneal wounds healing. Designing new recipes must consider technical achievements mentioned above. Considering above design requirements, we need a polymer adhesive that can seal corneal wound rapidly and accurately restoring correct intra ocular pressure $(>80 \mathrm{mmHg})$ and must comprise sufficient viscosity allowing clinician for precise placement and workability (viscosity $<100 \mathrm{cP}) .{ }^{61}$ Moreover, polymer adhesive must restore structural integrity of patterned collagen fibrils to provide native corneal transparency to focus the lights accurately and most important elastic modulus of polymer adhesive must be greater than corneal tissue to negate any possibility of astigmatism. Solute diffusion properties, biocompatibility, microbial barrier and biosorption of wound exudate are additional designing essentials where beauty meets utility for corneal wound care. ${ }^{62}$ Fundamentals of corneal wound management require repairing lacerations and clear sealing of incisions with securing corneal transplants. Closings of LASIK flaps are other ophthalmic indicators where nanoadhesives may prove to be landmark success. Next age materials such as polymeric dendrimer provide unique solutions to special wound care such as in corneal and ophthalmic injuries. Biodendrimers ${ }^{63}$ made up of polyethylene glycol (PEG), succinic acid (SA) and polylactic acid (PLA) are unique biocompatible and degradable polymeric dendrimers that shows controlled hydrophilicity and cell attachment/detachment properties. ${ }^{64}$

Further, capability of peptide-ligation based soft cross-linking avoids complex photochemistry and procedural risks that makes this more amenable for clinical procedures. Peptide cross-linking provides additional support to physico-mechanical properties (e.g., modulus and plasticity) and fit for clinical response in situ. ${ }^{65}$ Peptide lock and cross links in hydrogel and adhesive used for corneal wound care further give possibility to peptidases based easy cleavage when it comes to integration of nano-domain 
protein or monomer in multigenerational biodendrimer synthesis ${ }^{66}$ (Figure 5).

\section{Nanobiomaterials for synthetic blad- der wall substitute}

A large number of populations suffer from cancer and disorders related to bladder. In absence of suitable surgical treatment and chemotherapeutic panic, removal of entire bladder wall is considered best strategy to prevent the recurrence of bladder cancer and disorders. Considering essentials of designing new materials, mimicking topographic features of bladder wall with stretchability, mechanical properties and optimal knowledge of cellular and molecular events in vivo, are the main requisite. ${ }^{67}$ Surface features of bladder gives an understanding of designing biological nanostructures, such as nano-dimension extra cellular matrix constituent proteins that should be precisely incorporated and tagged with the biological moieties to give maximal cell response. Researchers have designed nano-dimensional poly (latide-co-glycolide) acid (PLGA) and polyurethane (PU) based artificial structures mimicking bladder topography in 50-100 $\mathrm{nm}$ range those exhibit excellent in vitro cytocompatibility and enhanced bladder smooth muscle cell adhesion and proliferation. ${ }^{68}$ Designed materials show parallelism with in vivo functionality of natural bladder wall that opens new avenues for nanobiomaterials for designing tissue engineered artificial structures. ${ }^{69}$

\section{Nanobiomaterials in artificial blood vessel replacement: A special case of intravascular wound healing}

Apart from surface wound, deep vascular tissues often meet intra vascular tissue damage due to ischemia and perfusion such as in myocardial and endothelial injuries which need immediate clinical attention, being part of vital organ. ${ }^{69}$ More often cardiac procedures are supplement with bypass surgery of affected blood vessels with autologous arteries or veins of less than $6 \mathrm{~mm}$ diameter, in order to reduce procedural and invasive risk of heterologous grafts rejection. ${ }^{70}$ Many myocardial infarction patients need an alternative to innate blood vessels in coronary artery bypass graft surgery $(\mathrm{CABG})$ as a replacement to their diseased or sclerosed blood vessels. ${ }^{71}$ In this regard, the design strategy involving core technology must meet a number of cell construct in vitro that can precisely mimic the vessel architecture and land marks in vivo with respect to biochemical and biomechanical aspect. New age biomaterials and micro to nanoscale technologies provide artistic liberty to meet the precision in this regard by meticulously mounting biochemical building blocks. For example, artificial endothelial layer production needs cross linking of collagen fibers, integrated with growth factors needed for cell communications between different vessel wall layers. ${ }^{72}$ Lately, in vitro studies shown that radial stresses induced by cyclic stimulations give better mechanical strength and histological organizations in which cells get arranged circumferentially throughout the wall thickness like natural blood vessel wall. This mechanical stimulation plays a key role in precise netting and increasing collagen content in artificial structure compared to unstrained controls. ${ }^{72}$ Evidence to mechanical conditioning that stimulates cell mediated construct remodeling is demonstrated by over expression of matrix metalloproteinases (MMPs). These are expressed in relation with the production of ECM structural proteins (elastin and collagen) and reinforce the remodeled tissue. ${ }^{73}$ This is further supported by increased level of collagen and elastin mRNA content in mechanically stimulated and cyclically strained cells in vitro. ${ }^{74}$

Another most important factor that paves success of artificial design of blood vessels is cell technologies enabling pinpoint cell manipulation and their controlled functionality. ${ }^{75}$ These features can be further regulated by creating extracellular environment of embryonic cells (ECs) utilized for making synthetic grafts by encapsulating them in reconstituted collagen matrix, providing functional vaso-activity in biological scaffold. ${ }^{76}$ By inducing endothelialization in synthetic graft, it is possible to design an artificial blood vessel.
This construct should contain an outer adventitia made of fibroblast and collagen, a middle layer (media) made of mesenchymal stroma cells (MSCs) and ECs based internal monolayer (intima), when molded in tubular fashion.

\section{Insight into nanomaterials used for wound healing and tissue repair process \\ Nano-hydrogel in tissue repair: soft Nanochemistry in new role}

Hydrogels are hydrophilic, insoluble and swallowable materials; made up of natural (alginates/chitosan/agarose/chitosan/fibrin) or synthetic (Poly (acrylic acid) and its derivatives $;{ }^{77}$ poly (ethylene oxide) and its copolymers and polyvinyl pyrrolidine, polypeptides and their derivatives polymers. ${ }^{78}$ Hydrogel derived from biopolymers and designed as bioscaffold precisely mimic ECM in its chemical compositions comprising numerous amino acids, fibrous proteins, growth factors and sugar. Designed hydrogels also contribute to ECM functions by bringing cell junction together, recruiting growth factors for cell communications, allowing extracellular metabolite/nutrient transport, and most important controlling cellular architecture in vitro. ${ }^{79}$ In last few decades, realization of artificial prosthetic organs ranging from dentin, cartilage, ligament, tendon, bone to soft vascular prosthetic implants (arteries, bladder, skin) have been made possible due to generous hydrogel based scaffolds. ${ }^{80}$

Lately, uses of hydrogel for wound healing and tissue repairs process have gain applause in medicine based on capability to design and control their physical properties as per tissue repair requirement and support
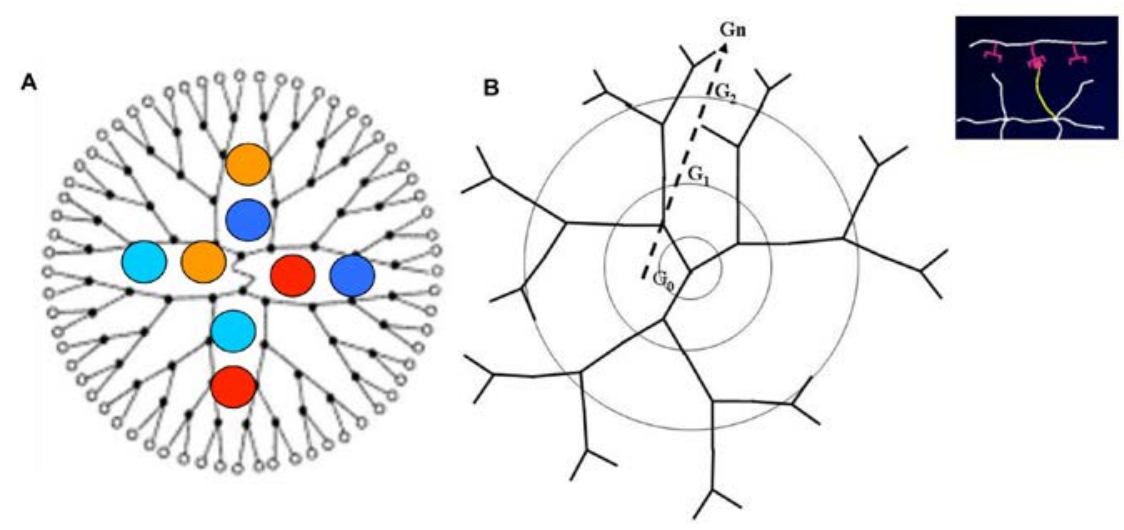

Figure 5. (A) Dendrimer with internal cavity, core and branching units with unique interior and surface chemistry to couple the therapeutic pay-load (colored dots show simultaneous loading of different drug molecule delivery at wound site). (B) Cartoon showing sequential addition of generations in those has advantages over controlling globular/linear/symmetrical faces of dendrimer to design 3-D architecture. Inset showing interaction of ligand-receptor complex at dendrimer surface (yellow line shows peptide spacer linked to ligands; Authors personal communication). 
for tissue remodeling. ${ }^{81}$ Hydrogels have been devised for occlusive dressing, cartilage tissue repair, and injectable cellular scaffold, axonal regeneration in spinal cord injury and tissue sealant in neurosurgery. ${ }^{82-86}$ Yet there are many open prospects those can serve for more advance use of hydrogel as novel nanomaterials for tissue repair. One novel strategy could be design of hydrogel-based bioscaffold comprising fibronectin functional domains (FNfds) and hyaluronan (HA) for tissue repair. Since FNfds hydrogel matrix is a tremendous medium for promoting wound healing by binding with the platelet derived growth factors (PDGFs), it assists with the fibroblast migration in situ that is a crucial step for tissue induction for remodeling of injured tissue. ${ }^{86,87}$ As mentioned above, hydrogel matrices are available in a wide range of designs from nanoporous, fibrous to fine network of embedded proteins. 3-D hydrogel matrices give a unique opportunity for designing artificial ECM pegged with growth factors and therapeutics required for rapid healing as shown in Figure 6.

Such designs, mimicking porous and fibrous ECM will support cell growth and migration by trapping fibroblast and other inflammatory cells required for tissue remodeling. ${ }^{88}$ More ambitious; 3-D hydrogel architecture housed with the cultured fibroblast with growth factors, acts as smart natural skin to establish aesthetic remodeling of lost skin in burn cases and massive injuries with severe tissue loss. ${ }^{89}$

\section{Electrospun polymers scaffold: tis- sue repair at the rate of spinning chemistry}

Biomaterial designers have given a new horizon to biomedicine by developing procedure to control nanostructure by introducing biocompatibility, mechanical stiffness, stability and biodegradability. Electrospinning, electrostatic and gas blowing technologies had given an edge to design nanowoven fibrous materials from organic/inorganic to biological polymers. Simultaneously we have control over porosity and diameter, mesh size, texture and pattern giving larger surface area and high surface to volume ratio (S/V) for biomedical and industrial applications. ${ }^{90}$ Nanofibrous materials have secured their application from medicine, cosmetics, tissue scaffold for implants to industrial purposes depending upon nanofiber shape, alignment and cross section that are exclusive features in selecting the fiber materials for a particular application. ${ }^{91}$ One of biggest advantage that we can count over use of electro spun scaffolds for wound healing and tissue repair process over native polymers is their physical resemblance with ECM in native tissue, which makes them a promising candidate for regenerative medicine. Electrospun ECM substratum camouflage gives an opportunity to assess cellular function in vitro and applications where such scaffolds are used as cell delivery vehicles and viable cell grafts. Compare to traditional polymer engineering techniques, electrospun polymer nanofibers involve controlling a vast array of parameters. This characteristic is tremendously important for their application in postoperative surgeries and stimulating tissue regenerations by promoting adhesion, proliferation, and differentiation cellular flora at the wound site. ${ }^{92}$ Further, electrospun materials fall in both i.e. natural and synthetic polymer categories. Clinicians have free option to choose best for our tissue repair mechanism that can either support physical (strength/durability) or biological (cell attachment and proliferations) functionalities, or both and indeed researchers had shown is past such subtle advantage while combining the two. ${ }^{93}$ Thus, above findings reveal the potential of electrospun polymer applications one-step ahead to develop the artificial skin and smart ECM Grafts for tissue repair in severe clinical crisis such as heavy burn and injuries involving massive muscular damage.

Recently polymer colloids have attracted much glare in biomedical applications due to their superior properties of design and feasibility to introduce branching and biodegradability. ${ }^{94,95}$ Polymer colloids are 100-400 nm diameters with great soft architectural diversity. Their ability to easy encapsulation,

modify hydrophilicity/hydrophobicity and sustained release at application site, makes them good candidate for their surgical use in arteries and connective tissue. Moreover, new
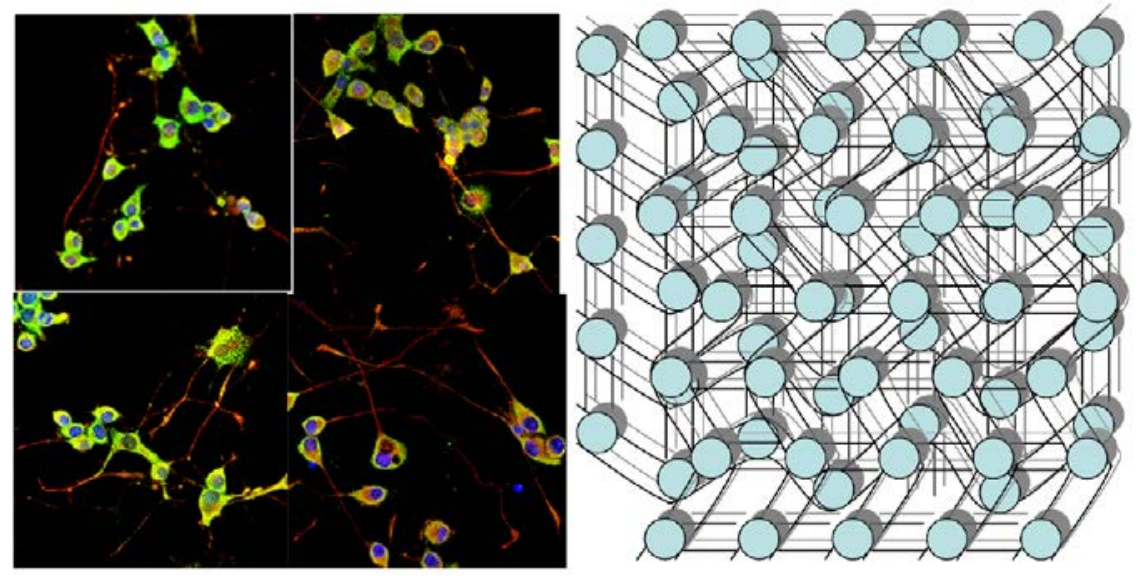

Figure 6. Image showing immunostained cells growing (left panel) fine network of hydrogel mesh (right panel) housing granulated collagen, growth, network of keratinocyte and chondroitin 6-sulphate as viable skin for wound repair (Authors personal work). categories of polymer colloids can be designed based on requisite as per biomedical applications. Polymer chemistry has given an opportunity to design resorbable colloids those could be used as promising wound dressing materials. ${ }^{96}$ In addition, resorbable colloids offer great commercial viability for clinical applications such as postoperative anti-adhesion resorbable colloids offer is that anti-adhesion biofilms that on one hand offers excellent biosorption barrier to prevent postoperative complications; on the other hand, it undergoes self-degradation when tissue remodeling is completed at augmented wound site.

Recently endothelial progenitor cell (EPCs) has been used as smart biomaterial composite for the control of microenvironmental cues since they promote differentiation, angiogenesis and bone marrow-derived endothelial progenitor cell mobility via secreting VEGF and VEGFR-2 factors. Circulating EPCs from human fetal aorta with strong self-renewal ability express CD133, CD34, and VEGFR2, which play a vital role in cure of diabetic foot in murine models. Transplantation of human fetal aorta (HFA)-derived EPCs has recently proved to be vital for treating microvascular dysfunction prevalent in diabetic vascular biology, could be useful for innovative therapeutic strategy for managing other vascular diseases. Easy availability and rapid expansion of adipose-derived stem cells (ASCs) from autologous adipose tissue with antiapoptotic factor, secretion of proangiogenesis, and capacity for multilineage differentiation has been used vascular tissue repair, rescue and vascular growth.

Apart from aforementioned applications, electrospun polymer scaffold have been used membranes in trauma. Another benefit these 
in many clinical emergencies as artificial implants for tissue repair. Electrospun nanofibres have been developed into different tissue scaffold combining cultured cells with natural and biocompatible materials depending upon clinical requirement as stated in Table 2.97-107

\section{Limitation, progress and prospect}

Development in nanomedicine had offered many opportunities to improve wound healing and tissue repair process due to progress in biomimetic approach to design bioactive nanomaterials with much closer to natural tissue with respect to structure and function. Research in this area have responded to long arguments in scientific community by putting forth rational advances to develop artificial skin and ECM analogues which can be an innovative supplant for future clinical emergencies needing commendable tissue repair back up. Recent advances in nanotechnology such as electrospinning have given liberty that is more artistic to researcher while designing the materials of clinical as well as aesthetic superiority.

Present review outlined the principal clinical requirement for wound healing and their subsequent challenges and applauding measures provided by recent developments in nanomedicine and materials science. Perspective arduous biomedical challenges and their possible solutions in designing artificial skin and ECM have been reported provided with ambitious progress in materials sciences. We also reported the use of nanobiomaterials in special clinical practices such as corneal wound, bladder wall and vascular biology applications where we need to put maximum precautions while developing new materials. In addition, details regarding state of the art nanobiomaterials such as dendrimer and polymers (electrospun and hydrogel) those have served in tissue repair process are mentioned. Artificial 3D cell culture from a modern neurobiology perspective is at infancy but provides a great hope for tomorrow, bringing relevance and meaning to cell based assays for different applications. Realizing the fact that cells in tissue operate in a 3D environment, switching to a $3 \mathrm{D}$ cell culture system will involve substantial time and cost, in terms of technology, and most importantly in throughput and scalability. ${ }^{108}$ The current state-of-the-art three dimensional culture and imaging in multiple planes involves detecting a 3D multicellular body most often embedded in a gel type, ECM mimic, or

Table 2. Represents electrospun nanofibers conjugated (using coupling chemistry) with the mammalian cells, natural and synthetic biocompatible materials for various tissue management clinical practices.

\begin{tabular}{ll}
$\begin{array}{l}\text { Clinical conditions } \\
\text { Nerve implants }\end{array}$ & Biomaterials \\
Vascular grafts & $\begin{array}{l}\text { Neuronal Stem Cell + Poly(L-lactic acid) }{ }^{97} \\
\text { Myofibroblasts, Arterial Smooth Muscle Cell } \\
\text { Human coronary artery endothelial cells, PLA, Collagen type I\&II, } \\
\text { Elastin }^{98,99}\end{array}$ \\
\hline Bone implant & $\begin{array}{l}\text { Osteoblast, Mesenchymal stem cells + } \\
\text { Silk/polyethylene oxide/hydroxyapatite / bone morphogenetic protein }{ }^{100}\end{array}$ \\
Cardiac implants & Cradiomyocytes and myoblasts + Polyaniline and gelatin, Polylactide ${ }^{101,102}$ \\
\hline $\begin{array}{l}\text { Human ligament Implants } \\
\text { Cartilage implants }\end{array}$ & $\begin{array}{l}\text { Ligament fibroblast + Polyurethane } \\
\text { Chondrocytes + Collagen Type II }{ }^{104}\end{array}$ \\
\hline Skin implants & $\begin{array}{l}\text { Human Fibroblast and Keratinocytes + Collagen type I coated with } \\
\text { collagen type I and laminin, Poly(lactide-co-glycolide) })^{12,105,106}\end{array}$ \\
Breast implants & $\begin{array}{l}\text { Human Fibroblast and Keratinocytes + Collagen type I } \\
\text { coated with collagen type I and laminin, Poly(lactide-co-glycolide) }{ }^{107}\end{array}$ \\
\hline
\end{tabular}

Table 3. Current organs-on-the chip devices with drawbacks in organ blue prints.

\begin{tabular}{|c|c|c|c|}
\hline Model & Cell niches & Organ blueprint & Drawbacks \\
\hline Blood brain barrier (BBB) & Astrocyte-endothelia & Tight Junctions and TEER & No human cell lines tested for barrier functionality \\
\hline Retinal blood barrier (RBB) & $\begin{array}{l}\text { Ocular vascular cells } \\
\text { and corneal epithelial cells }\end{array}$ & Epithelial barrier tight junctions & $\begin{array}{l}\text { Vitreous and mechanotransduction mechanism are } \\
\text { not explored }\end{array}$ \\
\hline Mammary gland & $\begin{array}{l}\text { Breast specific endothelial } \\
\text { fibroblast and epithelial cells }\end{array}$ & $\begin{array}{l}\text { Cancer model for metastasis } \\
\text { and tumor invasion }\end{array}$ & $\begin{array}{l}\text { Cancer molecular markers expression } \\
\text { is not validated }\end{array}$ \\
\hline Bone-marrow-on-a-chip & $\begin{array}{l}\text { Viable marrow tissue with } \\
\text { functional hematopoietic } \\
\text { niches }\end{array}$ & $\begin{array}{l}\text { Organ level marrow toxicity } \\
\text { responses to radiation and } \\
\text { protective effect of the radiation } \\
\text { counter measure drugs }\end{array}$ & $\begin{array}{l}\text { Interaction between bone components } \\
\text { such as lacunae, canaliculi missing }\end{array}$ \\
\hline Gastro-intestinal-tract (GIT) & Gut epithelial cells & $\begin{array}{l}\text { Intestinal absorption mechanism } \\
\text { screening of molecular markers }\end{array}$ & $\begin{array}{l}\text { Model lack mechanical stimuli mimicking } \\
\text { microvillus in gut }\end{array}$ \\
\hline Kidney & $\begin{array}{l}\text { Glomerular } \\
\text { Network } \\
\text { (Renal tubular epithelial cells) }\end{array}$ & Screening of molecular markers & Glomerular anatomy blueprint missing \\
\hline Lungs & $\begin{array}{l}\text { Airway epithelial cells } \\
\text { Alveolar epithelial cells } \\
\text { Pulmonary microvascular } \\
\text { endothelial cells }\end{array}$ & $\begin{array}{l}\text { Demonstration of lung inflammation } \\
\text { and extra pulmonary absorption } \\
\text { alveolar capillary interface }\end{array}$ & $\begin{array}{l}\text { Complex fabrication, live imaging } \\
\text { is challenging, hybrid model lacks } \\
\text { vascular network }\end{array}$ \\
\hline Liver & $\begin{array}{l}\text { Hepatocytes } \\
\text { Vascular endothelial cells } \\
\text { Fibroblasts }\end{array}$ & $\begin{array}{l}\text { Liver zone and sinusoid formation, } \\
\text { serum protein synthesis }\end{array}$ & $\begin{array}{l}\text { Model close to regeneration but lack capability as } \\
\text { independent implantable device }\end{array}$ \\
\hline
\end{tabular}


hanging in a drop type culture. ${ }^{109}$ Though existing systems continue to be plagued with issues of reproducibility and variability, the bandage pharmaceutical industry is focused on making great strides in this area of research. The challenge of recreating complex CNS functions such as cognition in the brain cannot be recapitulated via 3D patterning. This is due to microscale spatial heterogeneity and macroscopic architecture of the spinal cord and brain. It is however possible to reproduce organ-level functions and electro-kinetic responses by copying barrier functions. ${ }^{110}$ Adding complexity and functionality in the third dimension, further poses a hurdle for high-resolution imaging to determine spatiotemporal locations of cell-cell or tissue-tissue interfaces, similar to visualize processes in living organs.

In vitro $3 \mathrm{D}$ engineered tissue and its ongoing therapeutic applications so far have been vastly carried out on collagen-based scaffolds. ${ }^{111}$ However, the CNS has minimal fibrillary matrix and collagen in ECM compositions, rendering it difficult to extrapolate the results from an in-vivo perspective. Nanotemplate material fabrications, bottom-up nanoengineering and physicochemical modulations of the neuronal culture environment provides new opportunities

neuropharmacology. 20,24,108,112-119 For example, self-assembled bioactive peptides, derived from laminin when electrospun as nanofiber scaffolds provide long-term survival and differentiation of neural progenitors into neurons and astrocytes. The density of the laminin epitope in the third dimension is crucial for such fast differentiation and could be a neurotherapeutic target. ${ }^{120}$ Nanostructured surfaces integrated with micropatterns give qualitative versus quantitative information for prosthesis design to minimize bacterial growth and promote neuronal like cell growth. ${ }^{30,33,34,121}$ Multipartite micro- and nanocarrier designs could be used for targeted diagnostics and therapeutics (theranostics) for debilitating diseases like multiple sclerosis or brain tumors. ${ }^{10,20,23-25,122-127}$

\section{Organ-on-chip devices for current therapeutic development for human organs}

Organs-on-chips are microfabricated systems mimicking in vivo organ like features replicated onto PDMS or elastic silicone. The devices imitate key functional components of in-vivo organs to reiterate integrated organ-level physiology in vitro with microfluidic channels. ${ }^{128}$ The microdevices could be the future for absorption, distribution, metabolism, excretion, and toxicity (ADMET) testing of neurotherapeutic pharmacokinetics. Synthetic organ-on-chip systems could be further useful to create in vitro models of human neurodegenerative disorders to understand pathophysiological modulation under drug trials. Drug toxicities based on preclinical animal trials often fail to categorize the drug uptake between the human and animal models owing to speciesspecific molecular differences (e.g., membrane transports). In such circumstances, tissues or human cells are necessary to draw definite conclusions. Therefore, miniature-human-brain like devices, designed via integrating 3D patterning and microfluidics, may replace the conventional animal models for neuropharmaceutical and neurochemical applications, reducing the cost of drug trials in the future. With advances in microfluidics and microfabrication technology, it is possible to spatially pattern and connect multiple tissue types on single chip, creating functional humanoid model with connected organs like features on chip. The rise of bioengineered neuronal tissue network, it is possible to predict the outcome of drugorgan interactions in humans using organ on chip platform, negating shortcoming of genetic differences of animal models. ${ }^{129}$ Particularly, microengineering recipes for the assembly and operation of the microfluidically lined blood brain barrier-onchip systems have attracted more attention of the neuropharmacology industry. For example, microengineering principles of the silicone industry could be used to design a multilayered microfluidic device, lined with human endothelial cells separated by a thin porous flexible membrane from astrocytes, into two parallel elastomeric microchannel (Figure 7). BBB specific cells cultured under physiological flow and apico-basal polarity into these microdevices can be easily adapted to develop BBB-on-chip using facile experimental techniques to quantify BBB specific functionality on CHIP. ${ }^{110,130}$ The biohybrid engineered CHIP lined with selforganizing pluripotent cells, which could eventually segregate into distinct brain regions, further provides a tool for neuropharmacology as a prototype of neurodevelopmental disorders. ${ }^{130,131}$ In preliminary reports, hydrophobic and hydrophilic drug transport demonstrated on chip across the artificial blood brain barrier corroborates in vivo findings, supports understanding gene-gene interactions and nanoparticle-guided diagnostics. ${ }^{131,132}$

Many in vitro cerebral organoids produced via 3D dynamic culture that resemble miniature brains, faithfully exhibit CNS like characteristics. ${ }^{110}$ However, in vivo neurons surrounded by the extremely complex system of heterogeneous tissues are physiologically different. Therefore, BBBon-chip models lined with network of glial cells may put forth a low cost non-animal research initiative to test stress signaling in neurons and neurotransmitter uptake and recycling. In addition, axonal myelination, nourishment, and trophic support of glial cells could be shown as a minimal, synthetic functional unit to recapitulate a part of brain on CHIP module, refer to Table 3.

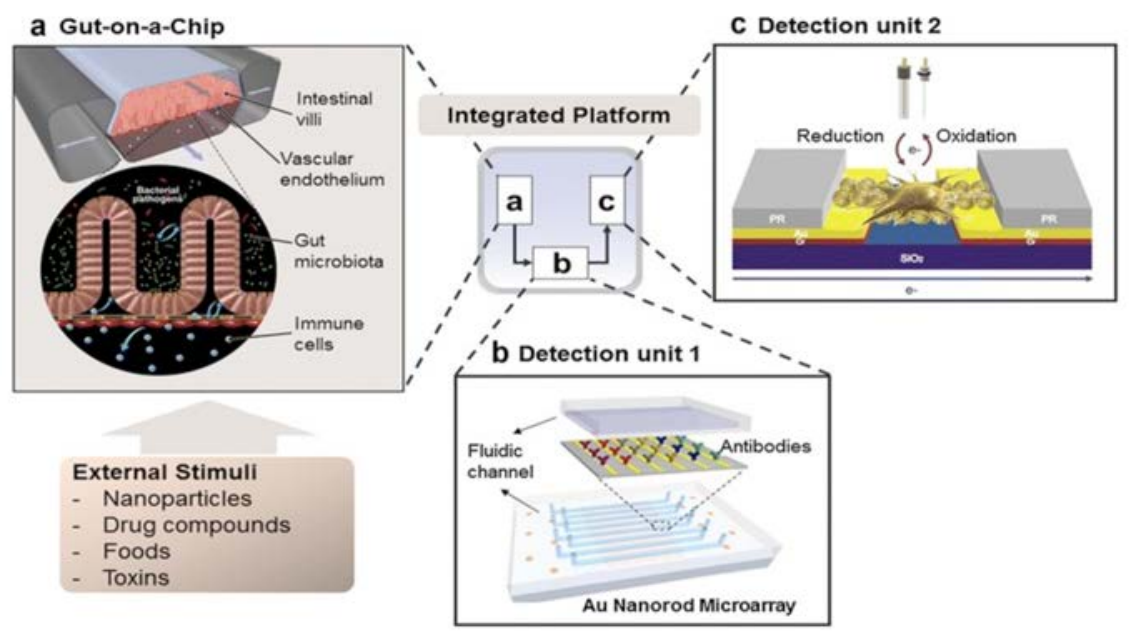

Figure 7. Concept of all human organ-on-a-chip. Advances in biomimetic micro engineering enable different organs features could be replicated on CHIP and to be integrated into a single micro device. Each further connected with each other via microfluidic circulatory system mimicking physiologically relevant functions as an in vitro model with complex, dynamic process into human body. Reproduced from ref. ${ }^{131}$ with free use Creative Commons Attribution 4.0 International License. 
Furthermore, combining the miniature brain on chip with 3D electrode array, intracellular transport, and axonal targeting may yield novel insight about calcium signaling and synaptogenesis. ${ }^{25}$

In lieu of organ-on-chip development, not only is there a paradigm shift in approach to research in the pharma industry but also public outreach of technology; especially in developing countries. With clinical trials, countless animal lives are lost amidst growing ethical concerns. In some instances, animal models used fail to predict human responses, as they are not physiologically relevant. Cutting edge research topics, such as the BBB-on-chip proposed herein could tremendously lower research budget for drug discovery and may boost sustainable development of therapeutics for poor rural populations of developing countries by helping researchers and scientists elucidate how tissues respond to new drug candidates. The BBB-on-chip model probably provide more understanding about BBB neurovascular unit, which will help to prevent current trend of $90 \%$ drug failure when switching from clinical trial from animal model to humans due to generic difference between the two. Furthermore, the BBB-on-chip could spearhead the development of in vitro therapeutic vaccines and drugs to counter infectious disease like cholera, diarrhea and tuberculosis, which contribute to high infant mortality in the rural parts developing countries.

\section{References}

1. Singh AV, Gade WN, Vats T, Lenardi C, Milani P. Nanomaterials: New generation therapeutics in wound healing and tissue repair. Curr Nanosci. $2010 ; 6: 577-86$.

2. Gupta AS. Nanomedicine approaches in vascular disease: a review. Nanomedicine. 2011;7:763-79.

3. Bender DJ, Fronek H, Arkans E. Quantified hemodynamics of compression garments. Veins and Lymphatics. 2013;2:10.

4. Jain KK. Research and Future of Nanomedicine. The Handbook of Nanomedicine 2017 (pp. 621-636). Humana Press, New York, NY.

5. Singh AV, Jahnke T, Kishore V, et al. Cancer cells biomineralize ionic gold into nanoparticles-microplates via secreting defense proteins with specific gold-binding peptides. Acta Biomater. 2018 Mar 1. pii: S1742-7061:300939.

6. Griffith M, Islam MM, Edin J, Papapavlou G, et al. The quest for anti- inflammatory and anti-infective biomaterials in clinical translation. Front Bioeng Biotechnol. 2016;4:71.

7. Shi J, Kantoff PW, Wooster R, Farokhzad OC. Cancer nanomedicine: progress, challenges and opportunities. Nat. Rev. Cancer 2017;17:20.

8. Yu MK, Park J, Jon S. Targeting strategies for multifunctional nanoparticles in cancer imaging and therapy. Theranostics. 2012;2:3.

9. Kesselheim AS, Avorn J. The most transformative drugs of the past 25 years: a survey of physicians. Nat Rev Drug Discov. 2013;12:425.

10. Singh A. Multiple sclerosis takes venous route: CCSVI and liberation therapy. Indian J Med Sci. 2010;64:337.

11. Tang L, Cheng J. Nonporous silica nanoparticles for nanomedicine application. Nano today. 2013;8:290312.

12. Dwivedi C, Pandey I, Pandey H, et al. In vivo diabetic wound healing with nanofibrous scaffolds modified with gentamicin and recombinant human epidermal growth factor. J Biomed Mater Res A. 2018;106:641-51.

13. Sheykhansari S, Kozielski K, Bill J, et al. Redox metals homeostasis in multiple sclerosis and amyotrophic lateral sclerosis: a review. Cell Death Dis. 2018;9:348.

14. Singh AV, Zamboni P. Anomalous venous blood flow and iron deposition in multiple sclerosis. J Cereb Blood Flow Metab. 2009;29:1867-78.

15. Vikram Singh A, Gharat $T$, Batuwangala $M$, et al. Threedimensional patterning in biomedicine: Importance and applications in neuropharmacology. J Biomed Mater Res B Appl Biomater. 2017.

16. Xie J, Owen T, Xia K, Singh AV, et al. Zinc Inhibits Hedgehog Autoprocessing Linking Zinc deficiency with hedgehog activation. J Biol Chem. 2015;290:11591-600.

17. Sadauskas E, Danscher G, Stoltenberg M, Vogel U, et al. Protracted elimination of gold nanoparticles from mouse liver. Nanomedicine. 2009;5:162-9.

18. Jalili NA, Muscarello M, Gaharwar AK. Nanoengineered thermoresponsive magnetic hydrogels for biomedical applications. Bioeng Transl Med.2016;1:297-305.

19. Berthet M, Gauthier Y, Lacroix C, Verrier B, Monge C. NanoparticleBased Dressing: The Future of Wound Treatment? Trends Biotechnol.2018;36:119.

20. Singh AV, Khare M, Gade WN,
Zamboni P. Theranostic implications of nanotechnology in multiple sclerosis: a future perspective. Autoimmune Dis. 2012;2012:1630.

21. Ratner BD, Hoffman AS, Schoen FJ, Lemons JE. Biomaterials science. MRS Bull. 2006;31:59.

22. Minuth WW, Sittinger M, Kloth S. Tissue engineering: generation of differentiated artificial tissues for biomedical applications. Cell Tissue Res. 1997;291:1-1.

23. Singh AV, Bandgar BM, Kasture M, Prasad BL, Sastry M. Synthesis of gold, silver and their alloy nanoparticles using bovine serum albumin as foaming and stabilizing agent. Journal of Materials Chemistry. 2005;15:5115-21.

24. Singh AV, Patil R, Kasture MB, Gade WN, Prasad BL. Synthesis of Ag-Pt alloy nanoparticles in aqueous bovine serum albumin foam and their cytocompatibility against human gingival fibroblasts. Colloids Surf B Biointerfaces. 2009 Mar 1;69(2):23945.

25. Singh AV, Mehta KK, Worley K, et al. Carbon nanotube-induced loss of multicellular chirality on micropatterned substrate is mediated by oxidative stress. ACS Nano. 2014;8:2196-205.

26. Ghanbari H, de Mel A, Seifalian AM. Cardiovascular application of polyhedral oligomeric silsesquioxane nanomaterials: a glimpse into prospective horizons. Int J Nanomedicine.2011;6:775.

27. Liu H, Webster TJ. Nanomedicine for implants: a review of studies and necessary experimental tools. Biomaterials. 2007;28:354-69.

28. Singh SP, Rathee N, Gupta H, Zamboni $\mathrm{P}$, Singh AV. Contactless and hassle free real time heart rate measurement with facial video. J Card Crit Care. 2017;1:024-9.

29. Singh AV, Baylan S, Park BW, Richter G, Sitti M. Hydrophobic pinning with copper nanowhiskers leads to bactericidal properties. Plos One. 2017;12:e0175428.

30. V Singh A, Patil R, Anand A, Milani P, Gade WN. Biological synthesis of copper oxide nano particles using Escherichia coli. Curr Nanosci. 2010;6:365-9.

31. Griffith LG, Naughton G. Tissue engineering-current challenges and expanding opportunities. Science. 2002;295:1009-14.

32. Singh AV, Vyas V, Maontani E, Cartelli $\mathrm{D}$, et al. Investigation of in vitro cytotoxicity of the redox state of ionic 
iron in neuroblastoma cells. J Neurosci Rural Pract. $2012 ; 3: 301$.

33. Singh AV, Vyas V, Patil R, Sharma V, et al. Quantitative characterization of the influence of the nanoscale morphology of nanostructured surfaces on bacterial adhesion and biofilm formation. PloS One. 2011;6:e25029.

34. Singh AV, Vyas V, Salve TS, Cortelli D, et al. Biofilm formation on nanostructured titanium oxide surfaces and a micro/nanofabrication-based preventive strategy using colloidal lithography. Biofabrication. 2012;4:025001.

35. Singh AV, Hosseinidoust Z, Park BW, Yasa O, Sitti M. Microemulsion-based soft bacteria-driven microswimmers for active cargo delivery. ACS Nano. 2017;11:9759-69.

36. Tabas I, Glass CK. Anti-inflammatory therapy in chronic disease: challenges and opportunities. Science. 2013 ;339:166-72.

37. Someya T, Sekitani T, Iba S, Kato Y, Kawaguchi $\mathrm{H}$, et al. A large-area, flexible pressure sensor matrix with organic field-effect transistors for artificial skin applications. Proc Natl Acad Sci U S A. 2004;101:9966-70.

38. Basheer IA, Hajmeer M. Artificial neural networks: fundamentals, computing, design, and application. J Microbiol Methods. 2000 ;4:3-1.

39. Hammock ML, Chortos A, Tee BC, Tok JB, Bao Z. 25th anniversary article: the evolution of electronic skin (eskin): a brief history, design considerations, and recent progress. Adv Mater. 2013;25: 5997-6038.

40. Yannas IV, Burke JF. Design of an artificial skin. I. Basic design principles. J Biomed Mater Res A. 1980 ;14:65-81.

41. Singh AV, Rahman A, Kumar NS, Aditi AS, et al. Bio-inspired approaches to design smart fabrics. Mater Des. 2012; 36:829-39.

42. Singer AJ, Clark RA. Cutaneous wound healing. N Engl J Med. 1999;341:73846.

43. Yannas IV, Burke JF, Gordon PL, Huang C, Rubenstein RH. Design of an artificial skin. II. Control of chemical composition. J Biomed Mater Res A. 1980;14:107-32.

44. Kirker KR, Luo Y, Nielson JH, Shelby J, Prestwich GD. Glycosaminoglycan hydrogel films as bio-interactive dressings for wound healing. Biomaterials. 2002;23:3661-71.

45. Wang LS, Chow PY, Phan TT, Lim IJ, Yang YY. Fabrication and characterization of nanostructured and thermosensitive polymer membranes for wound healing and cell grafting. Advanced Functional Materials. 2006;16:1171-8.

46. Dal Pozzo A, Vanini L, Fagnoni M, Guerrini $M$, et al. Preparation and characterization of poly (ethylene glycol)-crosslinked reacetylated chitosans. Carbohydr Polym. 2000;42:201-6.

47. Collier TO, Anderson JM. Protein and surface effects on monocyte and macrophage adhesion, maturation, and survival. J Biomed Mater Res A. 2002;60:487-96.

48. Berscht PC, Nies B, Liebendörfer A, Kreuter J. In vitro evaluation of biocompatibility of different wound dressing materials. J Mater Sci Mater Med.. 1995;6:201-5.

49. Daniels S, Sibbald RG, Ennis W, Eager CA. Evaluation of a new composite dressing for the management of chronic leg ulcer wounds. J Wound Care. 2002;11:290-4.

50. Lin SY, Chen KS, Run-Chu L. Design and evaluation of drug-loaded wound dressing having thermoresponsive, adhesive, absorptive and easy peeling properties. Biomaterials. 2001;22:29993004 .

51. Vermeulen H, Ubbink DT, Goossens A, De Vos R, Legemate DA. Systematic review of dressings and topical agents for surgical wounds healing by secondary intention. $\mathrm{Br} \mathrm{J}$ Surg. 2005;92:665-72.

52. Johnson FA, Craig DQ, Mercer AD, Chauhan S. The effects of alginate molecular structure and formulation variables on the physical characteristics of alginate raft systems. Int J Pharm. 1997;159:35-42.

53. Brownlee M. Biochemistry and molecular cell biology of diabetic complications. Nature. $2001 ; 414: 813$.

54. Singh AV. Biotechnological applications of supersonic cluster beamdeposited nanostructured thin films: Bottom-up engineering to optimize cell-protein-surface interactions. J Biomed Mater Res A. 2013;101:29943008 .

55. V Singh A, K Mehta K. Top-down versus bottom-up nanoengineering routes to design advanced oropharmacological products. Curr Pharm Des. 2016;22(11):1534-45.

56. Singh AV, Sitti M. Bacteria-Driven Particles:Patterned and Specific Attachment of Bacteria on Biohybrid Bacteria-Driven Microswimmers. Adv Healthc Mater. 18/2016;5:2325-31.

57. Teo WE, He W, Ramakrishna S. Electrospun scaffold tailored for tissue- specific extracellular matrix. Biotechnol J. 2006;1:918-29.

58. Hosseinidoust Z, Mostaghaci B, Yasa $\mathrm{O}$, et al. Bioengineered and biohybrid bacteria-based systems for drug delivery. Adv Drug Deliv Rev.2016;106:27-44.

59. Cook AD, Hrkach JS, Gao NN, Johnson IM, et al. Characterization and development of RGD-peptide-modified poly (lactic acid-co-lysine) as an interactive, resorbable biomaterial. J Biomed Mater Res A. 1997 ;35:513-23.

60. Shahinian L, Brown SI. Postoperative complications with protruding monofilament nylon sutures. Am J Ophthalmol. 1977;83:546-8.

61. Humphrey JD. Cardiovascular solid mechanics: cells, tissues, and organs. Springer Science \& Business Media; 2013 Jun 29.

62. Grinstaff MW. Designing hydrogel adhesives for corneal wound repair. Biomaterials. 2007;28:5205-14.

63. Grinstaff MW. Biodendrimers: new polymeric biomaterials for tissue engineering. Grinstaff MW. Biodendrimers: new polymeric biomaterials for tissue engineering. Chemistry-A European Journal. 2002 Jul. 2002;8:2838-46.

64. Carnahan MA, Grinstaff MW Synthesis and Characterization of Polyether- Ester Dendrimers from Glycerol and Lactic Acid. J Am Chem Soc. 2001;123:2905-6.

65. Wathier M, Johnson CS, Kim T, Grinstaff MW. Hydrogels formed by multiple peptide ligation reactions to fasten corneal transplants. Bioconjug Chem. 2006;17:873-6.

66. Zhao F, Zhao Y, Liu Y, Chang X, Chen C, Zhao Y. Cellular uptake, intracellular trafficking, and cytotoxicity of nanomaterials. Small. 2011;7:1322-37.

67. Kasza KE, Rowat AC, Liu J, Angelini TEet al. The cell as a material. Curr Opin Cell Biol. 2007;19:101-7.

68. Thapa A, Miller DC, Webster TJ, Haberstroh KM. Nano-structured polymers enhance bladder smooth muscle cell function. Biomaterials. 2003;24:2915-26.

69. Forman MB, Puett DW, Virmani R. Endothelial and myocardial injury during ischemia and reperfusion: pathogenesis and therapeutic implications. J Am Coll Cardiol. 1989;13:450-9.

70. Tu JV, Pashos CL, Naylor CD, Chen E, et al. Use of cardiac procedures and outcomes in elderly patients with myocardial infarction in the United States and Canada. N Engl J Med. 1997; 
336:1500-5.

71. Conte MS. The ideal small arterial substitute: a search for the Holy Grail?. FASEB J. 1998;12:43-5.

72. Rocko JM, Swan KG. Biomaterials in peripheral vascular surgery. Biomaterials. 1981 Jul 1;2(3):177-8.

73. Kim BS, Nikolovski J, Bonadio J, Mooney DJ. Cyclic mechanical strain regulates the development of engineered smooth muscle tissue. Nat Biotechnol. 1999;17:979.

74. Seliktar D, Galis ZG, Nerem RM. In vitro remodeling of cell-seeded collagengel vascular constructs in response to a uniquely defined mechanical environment. 4th Int. Conf. Cell. Eng., Nara, Japan.

75. Girling JE, Rogers PA. Recent advances in endometrial angiogenesis research. Angiogenesis. 2005;8:89-99.

76. Weinberg CB, Bell E. A blood vessel model constructed from collagen and cultured vascular cells. Science. 1986;231:397-400.

77. Pham QP, Sharma U, Mikos AG. Electrospinning of polymeric nanofibers for tissue engineering applications: a review. Tissue Eng. 2006;12:1197-211.

78. Lee KY, Mooney DJ. Hydrogels for tissue engineering. Chem Rev. 2001 ;101:1869-80.

79. Kim BS, Mooney DJ. Development of biocompatible synthetic extracellular matrices for tissue engineering. Trends Biotechnol. 1998;16:224-30.

80. Hoffman AS. Hydrogels for biomedical applications. Adv Drug Deliv Rev. 2012;64:18-23.

81. Lambert MA, Belch JJ. Medical management of critical limb ischaemia: where do we stand today?. J Intern Med. 2013 ;274:295-307.

82. Eisenbud D, Hunter H, Kessler L, Zulkowski K. Hydrogel wound dressings: where do we stand in 2003?. Ostomy Wound Manage. 2003 ;49:527.

83. Kisiday J, Jin M, Kurz B, Hung H, et al. Self-assembling peptide hydrogel fosters chondrocyte extracellular matrix production and cell division: implications for cartilage tissue repair. Proc Natl Acad Sci U S A. 2002 ;99:9996-10001.

84. Eaglstein WH. Moist wound healing with occlusive dressings: a clinical focus. Dermatol Surg.2001;27:175-82.

85. Cai S, Liu Y, Shu XZ, Prestwich GD. Injectable glycosaminoglycan hydrogels for controlled release of human basic fibroblast growth factor. Biomaterials. 2005 ;26:6054-67.
86. Preul MC, Bichard WD, Muench TR, Spetzler RF. Toward optimal tissue sealants for neurosurgery: use of a novel hydrogel sealant in a canine durotomy repair model. Neurosurgery. 2003; 53:1189-99.

87. Ghosh K, Ren XD, Shu XZ, Prestwich GD, Clark RA. Fibronectin functional domains coupled to hyaluronan stimulate adult human dermal fibroblast responses critical for wound healing. Tissue Eng. 2006;12:601-13.

88. Luo Y, Shoichet MS. A photolabile hydrogel for guided three-dimensional cell growth and migration. Nat Mater. 2004;3:249.

89. Schmidt CE, Baier JM. Acellular vascular tissues: natural biomaterials for tissue repair and tissue engineering. Biomaterials. 2000;21:2215-31.

90. Huang ZM, Zhang YZ, Kotaki M, Ramakrishna S. A review on polymer nanofibers by electrospinning and their applications in nanocomposites. Compos Sci Technol. 2003 63:2223-53.

91. Burger C, Hsiao BS, Chu B. Nanofibrous materials and their applications. Annu. Rev. Mater. Res. 2006 ;36:333-68.

92. Matthews JA, Wnek GE, Simpson DG, Bowlin GL. Electrospinning of collagen nanofibers. Biomacromolecules. 2002 ;3:232-8.

93. Chen G, Sato T, Ushida T, Ochiai N, Tateishi T. Tissue engineering of cartilage using a hybrid scaffold of synthetic polymer and collagen. Tissue Eng. 2004 ;10:323-30.

94. Mura S, Nicolas J, Couvreur P. Stimuliresponsive nanocarriers for drug delivery. Nat Mater. $2013 ; 12: 991$.

95. Rosenthal A, Barry JJ, Sahatjian R, inventors; Boston Scientific Scimed Inc, assignee. Triggered release hydrogel drug delivery system. United States patent US 7,066,904. 2006 Jun 27.

96. Finne-Wistrand A, Albertsson AC. The use of polymer design in resorbable colloids. Annu. Rev. Mater. Res. 2006;36:369-95.

97. Yang F, Xu CY, Kotaki M, Wang S, Ramakrishna S. Characterization of neural stem cells on electrospun poly (L-lactic acid) nanofibrous scaffold. J Biomater Sci Polym Ed. 2004 ;15:148397.

98. Huang L, Nagapudi K, P. Apkarian R, Chaikof EL. Engineered collagen-PEO nanofibers and fabrics. J Biomater Sci Polym Ed.2001;12:979-93.

99. Vaz CM, Van Tuijl S, Bouten CV, Baaijens FP. Design of scaffolds for blood vessel tissue engineering using a multi-layering electrospinning technique. Acta Biomater. 2005 ; 1:57582.

100. Li C, Vepari C, Jin HJ, Kim HJ, Kaplan DL. Electrospun silk-BMP-2 scaffolds for bone tissue engineering. Biomaterials. 2006 ;27:3115-24.

101. Li M, Guo Y, Wei Y, MacDiarmid AG, Lelkes PI. Electrospinning polyanilinecontained gelatin nanofibers for tissue engineering applications. Biomaterials. 2006 ;27:2705-15.

102.Zong X, Bien H, Chung CY, Yin L, Fang D, Hsiao BS, Chu B, Entcheva E. Electrospun fine-textured scaffolds for heart tissue constructs. Biomaterials. $2005 ; 26: 5330-8$.

103. Lee CH, Shin HJ, Cho IH, Kang YM, Kim IA, Park KD, Shin JW. Nanofiber alignment and direction of mechanical strain affect the ECM production of human ACL fibroblast. Biomaterials. $2005 ; 26: 1261-70$.

104. Shields KJ, Beckman MJ, Bowlin GL, Wayne JS. Mechanical properties and cellular proliferation of electrospun collagen type II. Tissue Eng. 2004;10: 1510-7.

105. Min BM, You Y, Kim JM, Lee SJ, Park WH. Formation of nanostructured poly (lactic-co-glycolic acid)/chitin matrix and its cellular response to normal human keratinocytes and fibroblasts. Carbohydr Polym. 2004 ;57:285-92.

106. Rho KS, Jeong L, Lee G, Seo BM, et al. Electrospinning of collagen nanofibers: effects on the behavior of normal human keratinocytes and early-stage wound healing. Biomaterials. 2006 ;27:1452-61.

107. Schindler M, Ahmed I, Kamal J, NurE-Kamal A, et al. A synthetic nanofibrillar matrix promotes in vivolike organization and morphogenesis for cells in culture. Biomaterials. 2005 ;26:5624-31.

108. Singh AV, Patil R, Thombre DK, Gade WN. Micro-nanopatterning as tool to study the role of physicochemical properties on cell-surface interactions. J Biomed Mater Res A. 2013;101:301932.

109. Huh D, Hamilton GA, Ingber DE. From 3D cell culture to organs-on-chips. Trends Cell Biol. 2011 ;21:745-54.

110. Gidwani M, Singh AV. Nanoparticle enabled drug delivery across the blood brain barrier: in vivo and in vitro models, opportunities and challenges. Curr Pharm Biotechnol. 2013 ;14:120112.

111. Hribar KC, Meggs K, Liu J, Zhu W, et al. Three-dimensional direct cell patterning in collagen hydrogels with 
near-infrared femtosecond laser. Sci Rep.. $2015 ; 5: 17203$.

112. Théry M. Micropatterning as a tool to decipher cell morphogenesis and functions. J Cell Sci. 2010 ;123:420113.

113. Singh AV, Lenardi CR, Gailite LA, Gianfelice AN, Milani PA. A simple liftoff-based patterning method for micro-and nanostructuring of functional substrates for cell culture. J Micromech Microeng. 2009 ;19:115028.

114. Singh AV. Biotechnological applications of supersonic cluster beamdeposited nanostructured thin films: Bottom-up engineering to optimize cell-protein-surface interactions. J Biomed Mater Res A. 2013 ;101:29943008.

115. Lim CK, Singh A, Heo J, Kim D, et al. Gadolinium-coordinated elastic nanogels for in vivo tumor targeting and imaging. Biomaterials. 2013 ;34:684652.

116. Singh AV, Gailite L, Vyas V, Lenardi C, et al. Rapid prototyping of nano-and micro-patterned substrates for the control of cell neuritogenesis by topographic and chemical cues. Mater. Sci. Eng.: C. $2011 ; 31: 892-9$.

117. Singh AV, Maheshwari S, Giovanni D, Naikmasur VG, et al. Nanoengineering approaches to design advanced dental materials for clinical applications. J. Bionanosci. 2010 ;4:53-65.

118. Hassan S, Singh AV. Biophysicochemical perspective of nanoparticle compatibility: a critically ignored parameter in nanomedicine. $\mathrm{J}$ Nanosci Nanotechnol. 2014 ;14:402-14.
119. Singh AV, Subhashree L, Milani P, Gemmati D, Zamboni P. Interplay of iron metallobiology, metalloproteinases, and FXIII, and role of their gene variants in venous leg ulcer. Int J Low Extrem Wounds. 2010;9:166-79.

120. Silva GA, Czeisler C, Niece KL, Beniash E, et al. Selective differentiation of neural progenitor cells by high-epitope density nanofibers. Science. 2004 ;303:1352-5.

121. Singh AV, Galluzzi M, Borghi F, Indrieri $\mathrm{M}$, et al. Interaction of bacterial cells with cluster-assembled nanostructured titania surfaces: An atomic force microscopy study. J Nanosci Nanotechnol. 2013 ;13:77-85.

122. Singh AV, Batuwangala M, Mundra R, Mehta K, et al. Biomineralized anisotropic gold microplatemacrophage interactions reveal frustrated phagocytosis-like phenomenon: a novel paclitaxel drug delivery vehicle. ACS Appl Mater Interfaces. $2014 ; 6: 14679-89$.

123. Gemmati D, Zeri G, Orioli E, De Gaetano FE, et al. Polymorphisms in the genes coding for iron binding and transporting proteins are associated with disability, severity, and early progression in multiple sclerosis. BMC Med Genet. 2012;13:70

124. Khare M, Singh AV, Zamboni P. Prospect of brain machine interface in motor disabilities: the future support for multiple sclerosis patient to improve quality of life. Ann Med Health Sci Res. 2014;4:305-12.

125. Vikram Singh A. Editorial (Thematic issue: Recent trends in nanobiotechnology reinforcing contemporary pharmaceutical design). Curr Pharm Des. 2016 ;22:1415-7.

126. V Singh A, K Mehta K. Top-down versus bottom-up nanoengineering routes to design advanced oropharmacological products. Curr Pharm Des. 2016;22:1534-45.

127. Vikram Singh A, Sitti M. Targeted drug delivery and imaging using mobile milli/microrobots: A promising future towards theranostic pharmaceutical design. Curr Pharm Des. 2016;22:141828.

128. Bhatia SN, Ingber DE. Microfluidic organs-on-chips. Nat Biotechnol. 2014; 32:760.

129. Fine B, Vunjak-Novakovic G. Shortcomings of Animal Models and the Rise of Engineered Human Cardiac Tissue. ACS Biomater Sci Eng. 2017 ;3:1884-97.

130. Lancaster MA, Renner M, Martin CA, Wenzel D, et al. Cerebral organoids model human brain development and microcephaly. Nature. 2013;501:373.

131. Choi JH, Lee J, Shin W, Choi JW, Kim HJ. Priming nanoparticle-guided diagnostics and therapeutics towards human organs-on-chips microphsiological system. Nano Converg. 2016; $3: 24$.

132. Tisato et al. Gene-gene interactions among coding genes of ironhomeostasis proteins and APOE-alleles in cognitive impairment diseases. PLoS One. 2018;13:e0193867. 